\title{
Influence of different water types on the physical and mechanical properties of gypsum
}

\author{
Juliana dos Santos Proença ${ }^{1}$, Marcos Massahiro Suzuki ${ }^{1}$, Silvano Cesar da Costa ${ }^{2}$, Bruno Shindi Hirata ${ }^{1}$, \\ Murilo Baena Lopes ${ }^{1}$, Edwin Fernando Ruiz Contreras ${ }^{1}$ \\ ${ }^{1}$ Universidade Estadual de Londrina - UEL, School of Dentistry, Department of Restorative Dentistry, Londrina, PR, Brazil \\ ${ }^{2}$ Universidade Estadual de Londrina - UEL, Department of Statistics, Londrina, PR, Brazil
}

Received for publication: May, 282015 Accepted: September, 182015

Correspondence to: Edwin Fernando Ruiz Contreras Departamento de Odontologia Restauradora Clínica Odontológica Universitária Universidade Estadual de Londrina - UEL Rua Pernambuco 540, Centro CEP: 86020-120 Londrina, PR, Brasil Phone: +55 43 3371-6750 Fax: +55 43 3371-6755 E-mail: edwin@uel.br

\begin{abstract}
Aim: To evaluate if gypsum mixed with different water types, with their different compositions influence the dimensional change, surface roughness and compressive strength of type IV and $\checkmark$ gypsum specimens. Methods: Sixty specimens were fabricated from metal matrices and divided into six groups $(n=10)$ according to the used type of gypsum and water: $G 1, G 2$ and $G 3$ - type IV gypsum and tap, mineral and distilled water, respectively; G4, G5 and G6 - type V gypsum and tap, mineral and distilled water, respectively. Water/powder ratio followed the manufacturer's recommendations $(19 \mathrm{~mL} / 100 \mathrm{~g})$ in all groups. The same specimens were used for all tests. A micrometer dial evaluated the dimensional change. The surface roughness of three random points was determined with a rugosimeter; a universal testing machine performed the compressive strength test. The data were subjected to analysis of variance (ANOVA). Results: There was no statistically significant difference $(p>0.05)$ between the three types of water in the studied variables. There was statistically significant difference $(p<0.05)$ between the gypsum mixes for the dimensional change variable. Conclusions: The different water types, with their different compositions, did not influence the analyzed physical and mechanical properties.
\end{abstract}

Keywords: calcium sulfate; water; compressive strength; dental prosthesis.

\section{Introduction}

Mold and model are essential to prosthetic rehabilitation and connect the clinical and the laboratorial phases required for dental prosthesis manufacture ${ }^{1}$. For dental treatment success, gypsum models should copy, as faithfully as possible, the desired structures contained in the mold ${ }^{2}$. Model accuracy is a critical factor in prostheses and indirect restorative manufacture. Hence, the tooth preparation must be reproduced accurately to obtain a correct marginal adaptation of these restorations. The gypsum model must have dimensional stability over time, abrasion resistance, fracture resistance ${ }^{1}$ and hardness ${ }^{3}$, properties that are very important during the manufacturing process ${ }^{1,3}$.

Type IV and V gypsum are widely used in fixed prostheses manufacture because they have strength and hardness needed during the sculpture wax pattern procedure. Type V gypsum has high setting expansion, therefore, it is indicated for material models that have high solidification contraction, such as basic metals, in order to offset this contraction ${ }^{4}$.

Some studies ${ }^{5-8}$ evaluated if the addition of certain substances to gypsum (calcium sulfate hemihydrate powder) or in water could change the setting expansion, surface hardness, setting time and compressive strength of gypsum 
specimens. Brukl et al. ${ }^{9}$ (1984) evaluated the effect of using different types of water in setting time and setting expansion of gypsum.

Different water types can be used to manipulate gypsum, such as tap, mineral and distilled water. Most dentists use tap water to manipulate gypsum powder. However, it may have mineral content variation depending of the city and of the sources within the same city, and water consumption of the population. Mineral water differs among commercial brands in its level of minerals ${ }^{10}$. On the other hand, distilled water is standardized, independent of commercial brand and has no mineral salts ${ }^{11}$. The main differences between the three types of water of interest to clinical dentistry are the mineral content and the cost, since tap water is cheaper than mineral ${ }^{11}$ and distilled water.

The research hypothesis was that the mineral salts in tap and mineral water react with the calcium sulfate hemihydrate powder, influencing the physical and mechanical properties of gypsum. Thus, distilled water would provide better results: less dimensional change and surface roughness, and higher compressive strength; improving the quality of the gypsum models and, consequently, of the final product.

The aim of this study was to evaluate if the mixture of gypsum powder with different water types, with their different mineral compositions, influence the dimensional change, surface roughness and compressive strength of type IV and $\mathrm{V}$ gypsum specimens.

\section{Material and methods}

\section{Gypsum specimens manufacture}

Type IV and V gypsum (Durone, Dentsply Ind. Comp. Ltda, Rio de Janeiro, RJ, Brazil) were weighed on a digital scale (Actlife, Balmak, Santa Bárbara d'Oeste, SP, Brazil) and mixed according to the ratio recommended by the manufacturer $(19 \mathrm{~mL} / 100 \mathrm{~g})$. Tap (Sanepar, Londrina, PR, Brazil), mineral (Cristal Safira, Maringá, PR, Brazil) and distilled water (SSplus, Maringá, PR, Brazil) were dosed using a $20 \mathrm{~mL}$ syringe. Gypsum and water were mechanically manipulated (Polidental, Model number 2191/06, Cotia, SP, Brazil) for $30 \mathrm{~s}$ to reach a homogeneous and smooth mix, avoiding possible air bubbles. The mix was poured into five identical metal matrices placed on a vibrator ( $\mathrm{VH}$ Equipamentos, Araraquara, SP, Brazil). The same calibrated operator produced all specimens.

\section{Group division}

Sixty specimens were obtained and divided according to the type of gypsum and water $(n=10)$. The same specimens were used for all tests:

Group 1: type IV gypsum and tap water Group 2: type IV gypsum and mineral water Group 3: type IV gypsum and distilled water Group 4: type V gypsum and tap water Group 5: type V gypsum and mineral water Group 6: type V gypsum and distilled water

\section{Tests}

The dimensional change was evaluated by a micrometer dial (Digimess Instrumentos de Precisão, São Paulo, SP, Brazil). The metal matrices used to make the specimens had a movable piece attached at the end, where the active tip of the micrometer touched. The needle of the micrometer was set on zero and the matrix was positioned against a concrete wall. When any change in gypsum volume occurred, the micrometer showed this change. The expansion was analyzed at $10,20,30$ and $40 \mathrm{~min}$; after this, the specimen was separated from the matrix.

The surface roughness of three random points was determined by a rugosimeter (Mitutoyo SurftestSJ-400 Series, Mitutoyo, Kawasaki, Kanagawa, Japan). The test was performed on the left specimen face that was in direct contact with the metal matrix, which provided a smooth standardized surface. The average of the three measurements was considered for statistical analysis. The unit and parameter selected were micrometers $(\mu \mathrm{m})$ and Ra, respectively. The arithmetic average of the existing peaks and valleys in a measurable length sets the $\mathrm{Ra}$ variable, which characterizes the average roughness of a surface ${ }^{12}$. In the present study, a $7.5 \mathrm{~mm}$ specimen length was measured.

The compressive strength was evaluated using a universal testing machine (EMIC DL2000, EMIC Equipamentos e Sistemas de Ensaio, São José dos Pinhais, PR, Brazil). After 7 days of fabrication, the dry strength was tested at crosshead speed of $1 \mathrm{~mm} / \mathrm{min}$ with the specimens placed vertically between two compression plates. The results were obtained in kilogram force (kgf).

\section{Statistical analysis}

The data were subjected to two-way ANOVA, using gypsum factor in two levels (IV and V) and water factor in three levels (tap, mineral and distilled water), totalizing 6 treatments with 10 repetitions each.

For the dimensional change variable, the result was observed at four different times - 10, 20, 30 and $40 \mathrm{~min}$ thus, longitudinal analysis with autoregressive correlation structure of $1^{\text {st }}$ order (AR1) was required for time modeling.

All assumptions for ANOVA validation according to the Shapiro-Wilk test for error normality were checked and met and Bartlett test for variance homogeneity. Differences were considered statistically significant at $p<0.05$.

\section{Results}

The mean values of dimensional change of type IV and $\mathrm{V}$ gypsum specimens can be observed in Figure 1. There was no statistically significant difference between the specimens prepared with the same gypsum type; on the other hand, the two gypsum types differ from each other $(p<0.05)$. The expansion values were lower for type IV than for type V gypsum (Table 1).

For dimensional change, the analysis of variance showed no statistically significant difference $(p>0.05)$ between the water types and for the water-gypsum interaction. 
Table 1. Mean dimensional change of type IV and V gypsum $(\mathrm{mm})$

\begin{tabular}{lcc}
\hline & Gypsum IV & Gypsum V \\
Tap Water & $0.07^{\mathrm{aA}}$ & $0.11^{\mathrm{aB}}$ \\
Mineral Water & $0.06^{\mathrm{aA}}$ & $0.11^{\mathrm{aB}}$ \\
Distilled Water & $0.07^{\mathrm{aA}}$ & $0.13^{\mathrm{aB}}$
\end{tabular}

Small letters compare the rows in each column. Capital letters compare the columns in each row. $p<0.05$ (ANOVA with autoregressive correlation structure of $1^{\text {st }}$ order).

The surface roughness analysis showed no statistically significant difference $(p>0.05)$ between the water types, gypsum types and their interaction (Table 2). The same was observed for the compressive strength variable (Table 3 ).

Table 2. Mean surface roughness of type IV and V gypsum (Ra).

\begin{tabular}{lc}
\hline Group (G) & Surface roughness (Ra) \\
G 1 & $1.59^{\mathrm{a}}$ \\
G 2 & $1.69^{\mathrm{a}}$ \\
G 3 & $1.59^{\mathrm{a}}$ \\
G 4 & $1.61^{\mathrm{a}}$ \\
G 5 & $1.56^{\mathrm{a}}$ \\
G 6 & $1.51^{\mathrm{a}}$ \\
\hline
\end{tabular}

Means followed by same small letters in each column do not differ statistically by two-way ANOVA ( $p>0.05)$.

Table 3. Mean compressive strength of type IV and V gypsum (kgf).

\begin{tabular}{lc}
\hline Group (G) & Compressive strength (kgf) \\
G 1 & $990.28^{\mathrm{a}}$ \\
G 2 & $120.18^{\mathrm{a}}$ \\
G 3 & $1135.18^{\mathrm{a}}$ \\
G 4 & $1171.68^{\mathrm{a}}$ \\
G 5 & $1308.42^{\mathrm{a}}$ \\
G 6 & $1384.84^{\mathrm{a}}$ \\
\hline
\end{tabular}

Means followed by same small letters in each column do not differ statistically by two-way ANOVA $(p>0.05)$.

\section{Discussion}

The gypsum (calcium sulfate hemihydrate powder) was mixed with three different types of water: tap, mineral and distilled. The tap water used in the research meets all requirements for drinking water. Mineral water has chemical, physical or physicochemical properties different from tap water and is enriched by certain minerals, such as calcium, fluoride, magnesium, chloride, carbonate, sodium, among others ${ }^{10}$. On the other hand, distilled water has no mineral salts ${ }^{11}$. Since the three types of water have different compositions, it was assessed if it could affect the dimensional change, surface roughness and compressive strength of gypsum specimens.

The expansion was analyzed at 10,20,30 and $40 \mathrm{~min}$ after manipulation of gypsum. According to Anusavice ${ }^{4}$ (2003), the final setting time Gilmore test shows that this occurs up to 20 min after gypsum and water mix and reported that, technically, the gypsum model is ready for use $30 \mathrm{~min}$ after manipulation. Clinically, mold and model are separated about 40 min after manipulation. Moreover, according to Marquezan et al. ${ }^{13}$ (2012), contact times of alginate with gypsum longer than $1 \mathrm{~h}$ damage the model surface, reducing detail reproduction and microhardness. Therefore, the present study reproduced and evaluated the dimensional change that is clinically more important. A possible reaction between the mineral water salts and calcium sulfate HEMIHYDRATED powder could cause an increase in model surface roughness, damaging the prosthetic work. Prostheses produced over rough models cannot accurately reproduce the details, which can cause clinically a misfit of the prosthesis. Thus, surface roughness is an important property to be evaluated in researches with gypsum models.

The present research results led to the conclusion that the study hypothesis was rejected, i.e. the mineral salts in tap and mineral water did not react with the calcium sulfate hemihydrate powder in order to influence the dimensional change, surface roughness and compressive strength of gypsum.

No significant differences between the studied water types for dimensional change was found for gypsum types IV and V. Similar behavior was observed by Brukl et al. ${ }^{9}$ (1984) who analyzed the influence of four water types, including tap and distilled water, in a type III gypsum with additives for setting time and setting expansion control. According to the authors, the additives minimize the variances caused by the different types of water in setting time and in setting expansion. Hiraguchi et al. ${ }^{14}$ (2003) investigated the effect of rinsing alginate impression using acidic electrolyzed water for mold disinfection, on the dimensional change of gypsum models. There were no statistically significant differences in dimensional change of gypsum models obtained by alginate molds rinsing with tap water and acidic electrolyzed water, for the same rinsing time.

In a previous study ${ }^{15}$ it was evaluated the dimensional accuracy of gypsum models (Durone IV) obtained from molds of three alginate impression materials that were disinfected by spraying and storage for $15 \mathrm{~min}$, with three solutions (2\% sodium hypochlorite, $2 \%$ chlorhexidine digluconate and $0.2 \%$ peracetic acid). There was no statistically significant difference between the disinfectant solutions and the alginate impression materials combination or for independent factors in the dimensional change of gypsum models. Another research ${ }^{13}$ showed that the time of contact between alginate and gypsum did not alter the model dimensions. Thus, the type of water, some methods of alginate mold disinfection, the alginate impression material and the time of alginate/ gypsum contact are factors that do not influence the dimensional change of gypsum.

In this study, the behavior of the gypsum type IV and V was different over time for the dimensional change variable. In the first 20 min both gypsum types had a growing expansion, which stabilized at this time on type IV gypsum. However, the type $\mathrm{V}$ gypsum changed remarkably until the final 40 min (Figure 1). The expansion values were lower for 


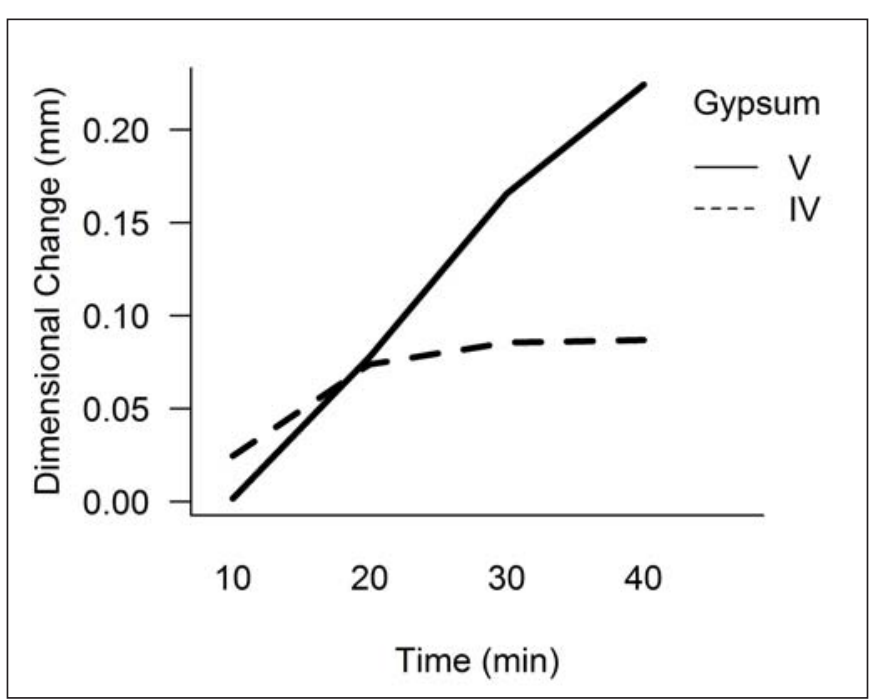

Fig. 1. Dimensional change variable: The setting expansion increased over time for type $V$ gypsum, showing a linear behavior. Unlike the type IV gypsum which showed a quadratic behavior, the setting expansion was more evident in the first $20 \mathrm{~min}$, stabilizing at this time. $p<0.05$ (ANOVA with autoregressive correlation structure of $1^{\text {st }}$ order).

type IV than for type V gypsum, as expected, because this material has high setting expansion ${ }^{4}$. The mean dimensional change to Durone IV was $0.032 \mathrm{~mm}$ in a study that analyzed the effect of dry gypsum specimens at room temperature $\left(25 \pm 4{ }^{\circ} \mathrm{C}\right)$ for $2 \mathrm{~h}^{16}$. In the present research, approximate values were also found to Durone IV specimens after $10 \mathrm{~min}$ of water/gypsum mix at room temperature. After the final setting time (40 $\mathrm{min})$, the mean dimensional change ranged from 0.08 to $0.09 \mathrm{~mm}$ (Table 4). It could be assumed that the difference between the mean dimensional change values occured due to the present study specimens being 3 times larger than previous study specimens, and to some variations in the measurement methods.

Table 4. Mean dimensional change per group, in $\mathrm{mm}$, to each measurement time.

\begin{tabular}{lllll}
\hline Group (G) & $10 \mathrm{~min}$ & $\mathbf{2 0} \mathrm{min}$ & $\mathbf{3 0} \mathrm{min}$ & $\mathbf{4 0} \mathrm{min}$ \\
G 1 & 0.02 & 0.07 & 0.08 & 0.09 \\
G 2 & 0.01 & 0.07 & 0.08 & 0.08 \\
G 3 & 0.04 & 0.09 & 0.09 & 0.09 \\
G 4 & 0.00 & 0.07 & 0.16 & 0.23 \\
G 5 & 0.00 & 0.07 & 0.15 & 0.21 \\
G 6 & 0.00 & 0.10 & 0.19 & 0.24 \\
\hline
\end{tabular}

In this research, there was no significant difference between the studied water and gypsum for surface roughness specimens. Moura et al. ${ }^{12}$ (2010) found that the alginate molds disinfection with sodium hypochlorite steam $(5.25 \%)$ for 10 min produced type III and IV gypsum specimens with dimensional stability similar to the control (untreated molds). This disinfection method did not influence either the surface roughness, which indicates that it is independent of the water type and alginate molds disinfection.

There was no statistically significant difference in compressive strength between the specimens prepared with tap, mineral and distilled water. Alsadi et al. ${ }^{5}$ (1996) evaluated if the use of gum arabic and calcium hydroxide would alter the compressive strength of improved die stone, but did not find differences between the specimens with or without this compound. Twomey et al. ${ }^{8}$ (2003) analyzed the type V gypsum mix with water containing different calcium hypochlorite disinfectant concentrations and found, in general, a decrease in compressive strength and a higher water demand to produce a material with the same consistency as the control, which resulted in specimens with greater porosity. This can be a cause for the decrease gypsum strength. However, the mix of type $\mathrm{V}$ gypsum and water containing $0.5 \%$ calcium hypochlorite increased dry strength and proved to be a good disinfectant that can be used in dental clinics $^{8}$. The type of water and the addition of gum arabic and calcium hydroxide to the gypsum powder are factors that neither improve nor decrease the compressive strength of gypsum. On the other hand, the type $\mathrm{V}$ gypsum mix can modify this variable with water containing calcium hypochlorite.

The three types of water showed no difference among themselves and did not alter the properties for both type IV and $\mathrm{V}$ gypsum, which means economic advantages to dentists, to prosthetics and even to patients, because there is no cost increase in gypsum models manufacture, and consequently, in the final product. Thus, good quality models can be obtained with tap, mineral and distilled water, provided that the technique is appropriate and the manufacturer's recommendations are followed.

The different water types, with their different mineral compositions, did not influence the analyzed physical and mechanical properties. We suggest that, despite different compositions, there is something common between them and their pureness that could influence these research results. Therefore, more studies are required to investigate the water purity, in order to determine whether there is something common between the tap, mineral and distilled water.

\section{Acknowledgements}

The authors would like to thank Rubens Nisie Tango, Ricardo Danil Guiraldo and Ricardo Alves Matheus for providing the apparatus necessary for the development of this research.

\section{References}

1. Dias SC, Moysés MR, Agnelli JAM, Ávila GB, Ribeiro JCR, Pereira LJ. Impact fracture strength applied to dental modeling materials. Braz J Oral Sci. 2007; 6: 1349-52.

2. Rudd KD, Morrow RM, Brown CE Jr., Powell JM, Rahe AJ. Comparison of effects of tap water and slurry water on gypsum casts. J Prosthet Dent. 1970; 24: 563-70.

3. Harris PE, Hoyer S, Lindquist TJ, Stanford CM. Alterations of surface hardness with gypsum die hardeners. J Prosthet Dent. 2004; 92: 35-8.

4. Anusavice KJ. Phillips' science of dental materials. Philadelphia: Saunders; 2003. 
5. Alsadi S, Combe EC, Cheng YS. Properties of gypsum with the addition of gum arabic and calcium hydroxide. J Prosthet Dent. 1996; 76: 530-4.

6. Diakoyanni IN, Kaloyannides AM, Panagiotouni EG. Dental stone and improved dental stone surface hardness: The effect of the addition of potassium salts. Eur J Prosthodont Restor Dent. 1992; 1: 79-85.

7. Zakaria MR, Johnston WM, Reisbick MH, Campagni WV. The effects of a liquid dispersing agent and a microcrystalline additive on the physical properties of type IV gypsum. J Prosthet Dent. 1988; 60: 630-7.

8. Twomey JO, Abdelaziz KM, Combe EC, Anderson DL. Calcium hypochlorite as a disinfecting additive for dental stone. J Prosthet Dent. 2003; 90: 282-8.

9. Brukl CE, McConnell RM, Norling BK, Collard SM. Influence of gauging water composition on dental stone expansion and setting time. J Prosthet Dent. 1984; 51: 218-23.

10. Azoulay A, Garzon P, Eisenberg MJ. Comparison of the mineral content of tap water and bottled waters. J Gen Intern Med. 2001; 16: 168-175.

11. Environmental Protection Agency (EPA). Bottled water basics. Washington: EPA; 2005 Sep. 9p. (Water Health Series).

12. Moura CDVS, Moura WL, França FMG, Martins GAS, Nogueira LBLV, Zanetti RV. Disinfection of irreversible hydrocolloid impressions with sodium hypochlorite steam: Assessment of surface roughness and dimensions of gypsum models. J Dent Sci. 2010; 25: 276-81.

13. Marquezan M, Jurach EM, Guimarães VD, Valentim RGA, Nojima LI, Nojima MCG. Does the contact time of alginate with plaster cast influence its properties? Braz Oral Res. 2012; 26: 197-201.

14. Hiraguchi $\mathrm{H}, \mathrm{Nakagawa} \mathrm{H}, \mathrm{Uchida} \mathrm{H}$, Tanabe $\mathrm{N}$. Effect of rinsing alginate impressions using acidic electrolyzed water on dimensional change and deformation of stone models. Dent Mater J. 2003; 22: 494-506.

15. Guiraldo RD, Borsato TT, Berger SB, Lopes MB, Gonini-Jr A, Sinhoreti MAC. Surface detail reproduction and dimensional acuraccy of stone models: Influence of disinfectant solutions and alginate impression materials. Braz Dent J. 2012; 23: 417-21.

16. Silva MAB, Vitti RP, Consani S, Sinhoreti MAC, Mesquita MF, Consani $\mathrm{RLX}$. Linear dimensional change, compressive strength and detail reproduction in type IV dental stone dried at room temperature and in a microwave oven. J Appl Oral Sci. 2012; 20: 588-93. 